\title{
Foreword
}

\section{Knee Osteotomies: A Powerful Tool}

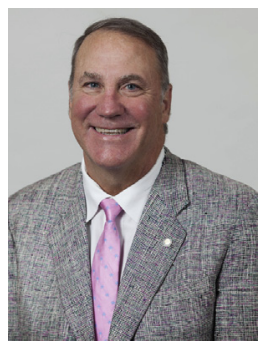

Mark D. Miller, MD Consulting Editor

A wedge is one of six classical simple machines originally described by Archimedes and further refined during the Renaissance era. Simple machines provide a mechanical advantage, and the wedge has been characterized as the most powerful of these simple machines or tools. According to Wikipedia, a wedge "...can be used to separate two objects or portions of an object, lift up an object, or hold an object in place". Osteotomies are based on this simple tool, and, when used thoughtfully and carefully, can have powerful results. However, like any tool, a wedge used improperly can have deleterious effects.

I can think of no two individuals that are more knowledgeable about this subject than Drs Ned Amendola and Davide Bonasia. Dr Amendola has been teaching me (and, for that matter, many of us) about osteotomies for decades. Dr Amendola, now Chief of Sports Medicine at our rival ACC school Duke, trained and taught in London, Ontario, Canada, which is what I would consider "The Osteotomy University" of North America. His co-editor, Dr Bonasia, is an internationally recognized expert on knee osteotomies from AO Ordine Mauriziano "Umberto I" Hospital, University of Torino, Italy. I am pleased that together they have taken this issue of Clinics in Sports Medicine to a new level.

This issue covers the gamut of osteotomies of the knee. Opening, closing, medial, lateral, tibial, femoral...you name it, and it is here, and all from experts in the field. 
So, I encourage you to read and study this issue of Clinics in Sports Medicine and apply this simple machine to complex problems about the knee in your practice.

Mark D. Miller, MD

Division of Sports Medicine

Department of Orthopaedic Surgery

University of Virginia

James Madison University

400 Ray C. Hunt Drive, Suite 330

Charlottesville, VA 22908-0159, USA

E-mail address:

mdm3p@virginia.edu 